We regard pain as a sensation which under certain conditions is superadded to the reflex, and the nerve impulses giving rise to pain we regard as excited by the same receptors and carried into the central nervous system by the same afferent neurones as those which bring about the reflex. Pain may be readily added to the reflex, as in the case of the afferent neurones from the cornea, or more rarely added, as in those from the heart muscle. The harmful stimulus, as has been shown by Sherrington, takes precedence of all others in bringing about its distinctive reflex, even in the spinal animal in which there can be no perception of pain. These observations appear to us to point to the reflex as the more important end-result of the harmful stimulus. In certain cases of injury to the spinal cord where areas of hyperalgesia are found in the skin the slightest stimulation of the latter results in pain. We cannot but conclude that here we are dealing with a central change, and that the nerve impulses excited at the periphery, which in the normal individual would cause no pain, now do so because of their more ready access to the pain tracts in the spinal cord. The actual cause of this increased passage of nerve impulses into the pain tracts appears to us to be explainable by a decreased resistance in the synapses between the endings of the afferent neurones and the dendrons of the neurones which constitute the pain fibres of the spinal cord. We know that the nerve impulses giving rise to pain are carried by fibres which decussate to the opposite side of the spinal cord soon after the impulses have reached the cord, and that this decussation is not made by the incoming afferent neuranes. Consequently there must be a synapse intervening between the incoming afferent neurone and the neurone which carries the impulses upwards on the opposite side of the spinal cord. This synapse, guarding as it were the entrance to the pain paths, is of great significance, for it interposes a resistance which is probably very varied for different afferent neurones, and is in each case susceptible to those changes which are characteristic of the synapses in general. So far as we know the afferent fibre on arrival in the lower level of the central nervous system gives off a number of branches and makes connexions with other neurones. Pathways are thus provided for a great many reactions.

It seems to us that neither pain from tissues endowed with common sensibility, nor from the viscera, requires special nerve fibres from the periphery, and that the analysis of the afferent nerve impulses takes place in the lower level of the central nervous system. Pain from tissues endowed with common sensibility becomes educated, capable of localization, and modified by other sensations. Pain from the viscera is comparatively rare, uneducated, unmodified by other sensations, and the nerve impulses which cause it, on coming into the lower level of the central nervous system, excite the same neurones in the pain paths and give rise to pain which is referred to those areas cf higher sensibility with which it has by education been associated.

There is, therefore, no necessity to postulate the separate existence of special receptors and special nerve fibres for the sense of pain. It is not indeed reasonable to assume that structures like the ureter and other viscera are provided with special receptors and special nerve fibres to meet a pathological event which may not occur for generations. The stimulus which is adequate to excite pain in the viscera or elsewhere may do far more than this. It sets up nerve impulses which spread widely in the lower level of the central nervous system, and may give rise to nausea, vomiting, sweating, vasomotor, cardiac, respiratory, and other reflexes, or even shock. Pain may or may not occur in association with any or all of these symptoms. Pain is a concomitant very often, but is not the cause.

Pain is one of the most important manifestations of ill health, and when it occurs is of special diagnostic value because the site of its excitation can be more or less definitely located. In this way a clue is given to the site and cause of the disturbance which is not to be obtained from the other symptoms occasioned by the spreading of the nerve impulses in the central nervous system.

\section{PELLAGRA IN CHILDREN IN ENGLAND.} (With Special Plate.)

BY

\author{
ROBERT HUTCHISON, AND DONALD PATERSON, \\ M.D., F.R.C.P., \\ PHYSICIAN, \\ M.B., M.R.C.P., \\ HOSPITAL FOR SICK CHILDREN, GREAT ORMOND STREET.
}

Ovr object in reporting two cases of pellagra in children is to draw the attention of clinicians in this country to the fact that pellagra is endemic in England.

The diagnosis, except in typical cases seen during the spring and summer months, when the rash is well marked, is not easy, and a considerable number of cases probably remain undiagnosed on this account. In 1913 and 1914 Dr. C. R. Box. described three cases of pellagra in children, two of them fatal. In one of these cases the pathology was described in detail by Sir Frederick Mott. All of these children had lived throughout life in England.

CaSE I.

Edna S., aged 6 years and 10 months, admitted to Great Ormond Street Hospital, April, 1923. The complaint was loss of walking power and shaking of the limbs. This had been noticed for six months. The family history appeared quite normal, no other person being affected. She was breast-fed for six weeks, then put on Nestlé's milk up to 11 months, since when she has had the same food as her parents. She had meat first at 3 years. She had always had plenty of milk, eggs, vegetables, and fruit. She was always fond of "cornflour" and would take nearly half a pint had lived at Little a healthy child up to the age of $3 \frac{1}{2}$ years. She had lived at Little Blackenham-ive miles beyond Ipswich-all her life except between the ages of 4 and $5 \frac{1}{2}$ years, when she had lived at Walthamstow. She had had "eczema " every year, starting in the spring. It was first noticed to occur after an illness, said to be "meningitis," at $3 \frac{1}{2}$ years of age. This illness lasted three months and was accompanied by fever and drowsiness; recovery was gradual. The rash appeared as the child got better. It appeared on
the hands, feet, neck, and face. It appeared on the knees last year for the first time. It usually lasted four to five months, appearing first in March. In July, 1922, the child complained of "giddiness," and began to fall about. This came on suddenly, the child falling down when out walking. She did not lose consciousness and the attack lasted one and $a$ half hours. A month later she had two similar attacks.

Present Illness.-The patient was comparatively well until six months ago, when she gradually ceased to walk more than a few steps, and tremor of her hands and arms developed. She walked with the aid of the furniture. She complains of pains in her head which seemed to start at the back of her neck and shoot over her head. Her eyesight failed and she could not recognize objects across the street. She had some frequency of micturition by day and night.

On admission, the child was miserable but well nourished. There were patches of dermatitis on the face, neck, hands and inner stirfaces of the arms, knees, and backs of the thighs. The tonsils were large and injected. There was incontinence of faeces. The were large and injected. There was incontinence of faeces. The and reacted to light. No cranial nerve palsy was noted. All her and reacted to light. No cranial nerve palsy was noted. All her deep reflexes were increased. The plantar reflexes gave a flexor
response, and the abdominal reflexes were not obtained. No ankle response, and the abdominal reflexes were not obtained. No ankle
clonus was elicited. There appeared to be a certain amount of anaesthesia to pin-pricks over the legs and abdomen, but there was no definite distribution and it was difficult to be sure. Her Wassermann reaction was negative. The cerebro-spinal fluid was normal. Her mental condition was very backward and she seemed to have the feeling that she was continually falling. Nothing definitely pathological was made out from an examination of the fundi. The urine contained a few cells and a trace of albumin. The urea concentration test showed a normal output of urea by the kidneys. The blood urea was normal : $37 \mathrm{mg}$. per $100 \mathrm{c.cm}$. The rash which was present had the appearance of a dermatitis produced by exposure to the sun. A test meal showed a well marked reduction exposure to the sun. A test meal showed a well marked reduction
of the total acidity of the gastric juice. No free hydrochloric of the total acidity
acid was present.

The patient was seen by Dr. L. W. Sambon, who stated that the distribution and character of the rash and nervous symptoms were typically those of pellagra. The child became much worse during died. Unfortunately no necropsy could be obtained.

\section{Case Ir.}

Helen S., aged 10 years and 9 months. Admitted to Great Ormond Street Hospital, July, 1922. The complaint was progressive mental deterioration and inability to walk, and in addition a rash on the hands, feet, face, and neck which came in the spring a rash on the hands, feet, face, and neck which came in the spring
and summer and disappeared in the winter. She has lived all her and summer and disappeared in the winter. She has lived all her life at Acton, a suburb of London, without leaving the district.
The mother and father are both alive and well. The patient is 


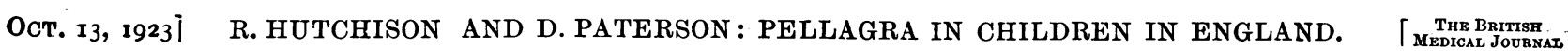

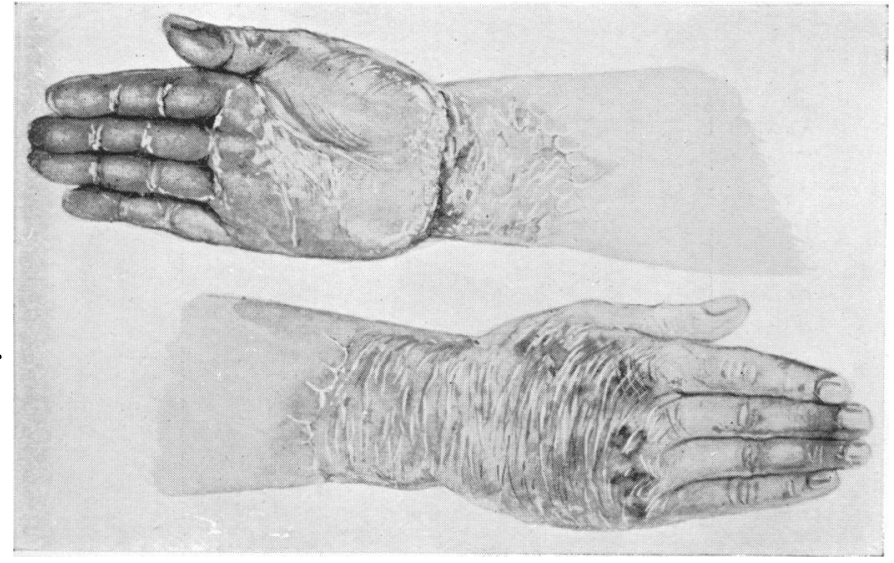

Frg. 1.-The hands and wrists in Case $\mathrm{I}$.

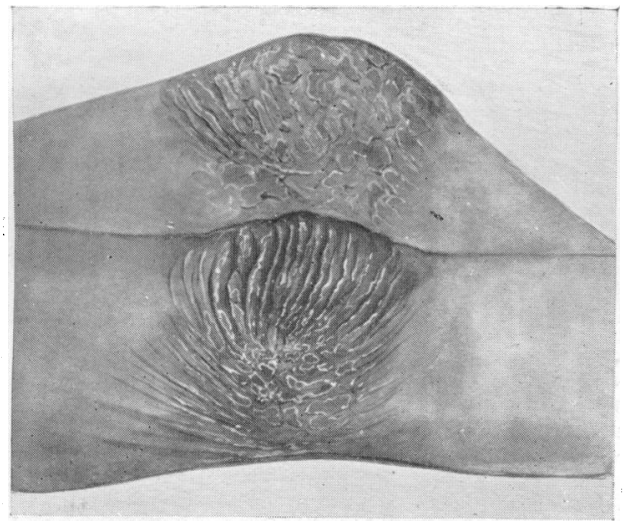

Frg. 2.-The knees in Case I.

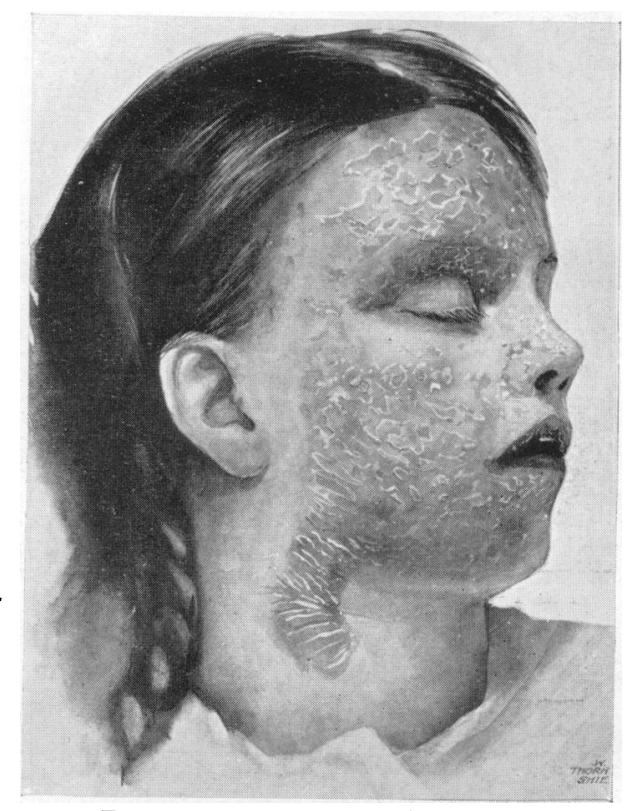

Fig. 3.-A ppearance of face in Case 1 .

SYDNEY SMITH AND MOHAMED EMARA: FRACTURE OF SKULL.

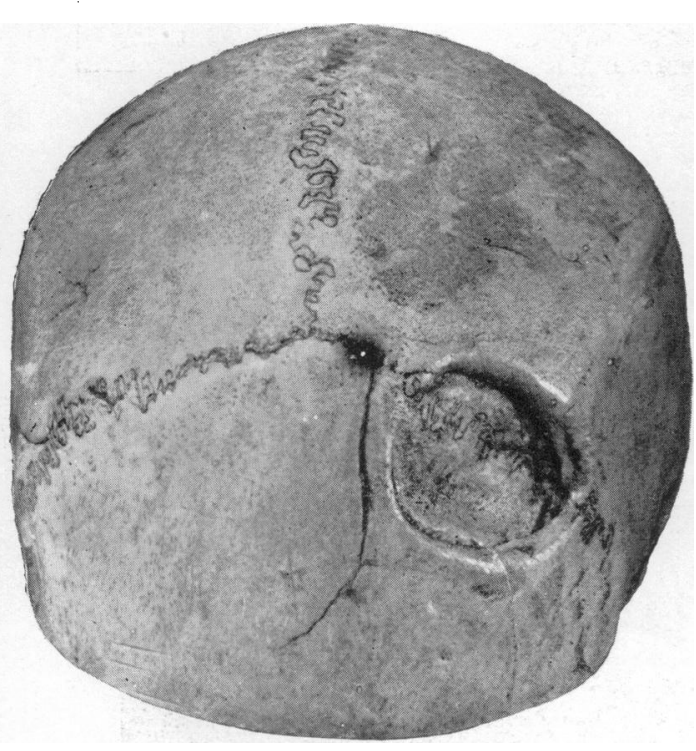

FIG 1.-Showing external aspect of bone,

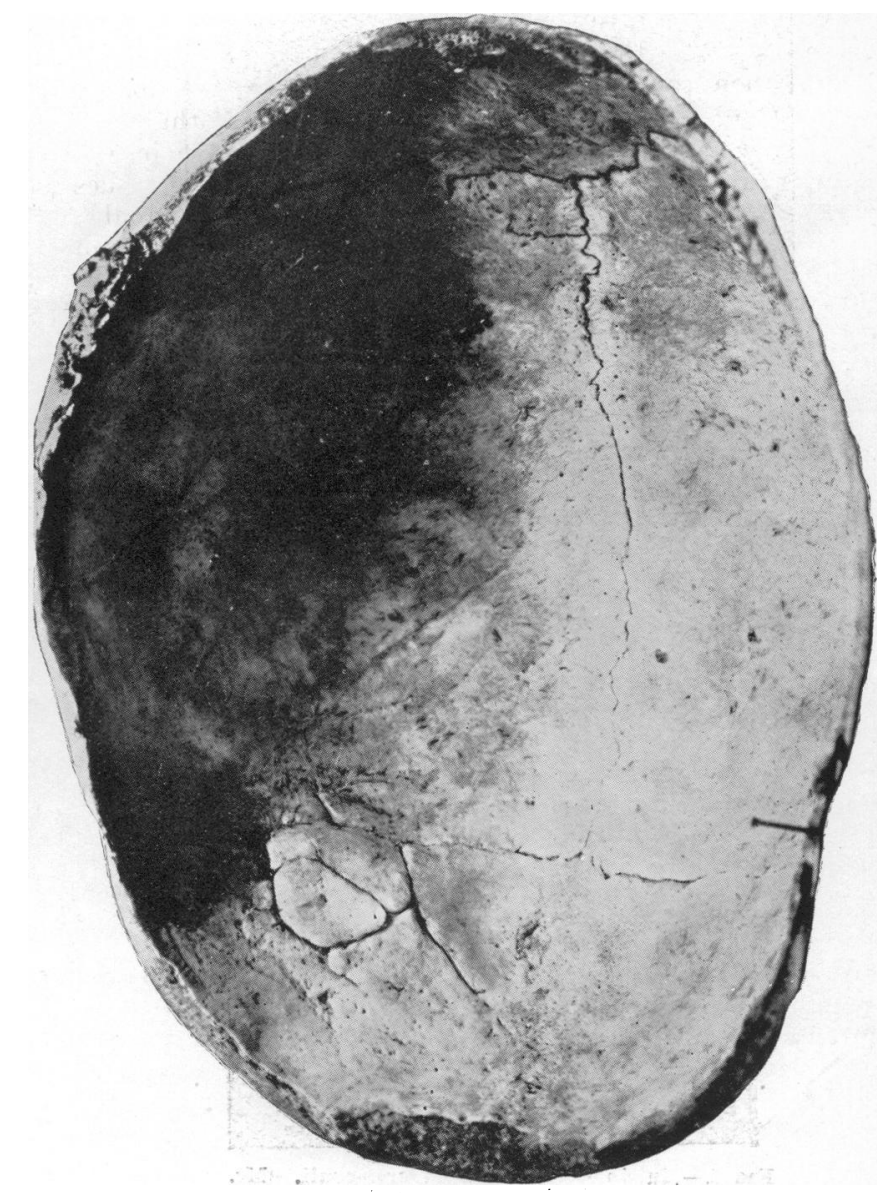

Fig 2.-Showing the internal aspect. 
the youngest of four children-the others are alive and well. Two of these children are said to have had rickets when quite young. The patient was a full-term child and fed for the first few weeks on the breast. She was then fe 1 on cow $s$ milk and water, on
which she developed diarrhoea at the age of 6 months. For the next few months she was fed on a diet consisting of arrowroot, cornflour, and water. For a number of years the child has taken a fairly full diet. The parents are of moderate means and her diet has been that of any other normal child. As a baby she had intraetable diarrhoea, since when she has always had to " leave the table in a hurry." Her bowels were inclined to be especially loose in the summer. She has had measles, mumps, and whooping-cough, all when quite young.

Present Illncss. - She first walked at 13 months, and her present difficulty seems to have dated from about her fifth year, when she started school. She has progressively become worse since. At one time she seemed quite normal mentally, but in the past three or four years she has become more and more "childish " and nervous. She has hallucinations of sight and hearing and has a continual fear of being murdered. She is inclined to repeat the same sentence over and over and is fast becoming more and more mentally backward. The rash was first noticed when quite young, perhaps at 3 or 4 years of age; certainly it has been present ever since 1915. Every spring her hands, feet, face, and neck become red and peeling and at times During the period the rash is present all the child's symptoms are aggravated.

On admission she was seen to be a well developed and moderately well nourished child. Her complexion was fair and her hair almost auburn. She had a dull face and it gave one the impression that she was mentally defective at the first glance. The most striking thing about her, however, was a red peeling condition of the whole of the face, neck, and exposed parts of the body, including the hands and feet and shins. In the popliteal spaces there was also well marked peeling. The skin felt harsh in these areas and was a sharp line where the red peeling condition suddenly there way to the normal white skin. Her mentality would be about that of a child of 3 or 4 . She was babyish in her speech and ways. She had marked hallucinations and believed that an attempt was being made to poison her. She was extremely emotional and cried for madil things in an unreasonable way. She screamed out at small things in an unreasonable way. She screamed out at night that someone was trying to cut her throat with a knife, or
was trying to poison her. Her reflexes were all exaggerated. The plantars were flexor, and pseudo-clonus was present. The ankle-jerks were brisk. There was no ocular paresis and no ptosis or strabismus was present. Her speech was slow and deliberate. She walked in a spastic manner and with a broad base, and seemed quite unable to lift her feet properly from the ground. As she walked she held her head forward and kept the arms held out from her sides as if to balance herself. Sensation was not impaired to heat, cold, or pain. All the cranial nerves were normal. Her co-ordination with her arms was good.

While in hospital she had recurring attacks of diarrhoea. The stools were loose, offensive, and contained slime and undigested food. At these periods she would lose her appetite. A test meal showed that her gastric acidity was about half that of the normal. Her cerebro-spinal fluid was normal and the Wassermann reaction in both this and the blood was negative. The blood count showed normal. An examination of her dises showed no neuritis.

By October, 1922, the rash had completely disappeared. The mental condition showed well marked improvement. She seemed to be walking better. In April, 1923, her mother wrote : "She is still about the same, walking about the house a little, but resting every minute. Her face is already burnt with the sun and peeling again. She continued to improve right up to the beginning of
March, but then her legs began to fail and she got tired very easily. March, but then her legs began to fai,

When shown at the Children's Section of the Royal Society of Medicine in the latter half of April the rash was not present of by keeping the child protected from the sun her mother had pre vented the reappearance of the rash to any extent. Mentally she seemed improved, but her walking was much the same as it had been ten months previously.

\section{Comment.}

In both these cases the rash and affection of the nervous system appear to be typical. Apart from the fact that at some period prior to the onset of symptoms both children were fed on large quantities of "cornflour," there is nothing in the history which would fit in with the various theories of the causation of pellagra. In Case II, at all events, the diet seemed to have contained a sufficiency of protein of high biological value.

These children had both resided all their lives in England and it is probable that the disease is commoner in this country than is at present realized, many cases remaining undiagnosed.

Bibliography.

Fatal Pellagrā in two English Boys, C. R. Box, Brirish Medical Journal, July 5th, 1913, pp. 2-4.

English Pellagra in Early Childhood, C. R. Box, British Medical Journal, August 29th, 1914, p. 397.

\section{A CASE OF FRACTURE OF THE SKULL CAUSING DEATH AFTER ELEVEN YEARS.}

(With Special Plate.)

BY

SYDNEY SMITH, M.D.EDIN,, D.P.H.,

PRINCIPAL MEDICO-LEGAL EXPERT, EG YPTIAN GOVERNMENT SERVICE;

AND

Dr. MOHAMED EMARA,

ASSISTANT MEDICO-LEGAL EXPERT.

The following case is of considerable medico-legal interest:

An Egyptian, aged about 40, when admitted, was said to have been struck on the head with a stick during a quarrel eleven years earlier. He was rendered unconscious and removed to hospital, where he remained for one month and was discharged cured without paralysis or other disability. For eleven years he worked as a labourer without having the slightest trouble.

On May 15th, 1923, while sitting with some friends he suddenly became unable to speak and felt numbness and heaviness in his right arm and leg. There had been no quarrel, no excitement, nor undue exertion. On May 16th he was taken to hospital. He was then semi-conscious, could understand a few words, and responded by indistinct syllables to all questions. There was no squint, no nystagmus, no conjugate deviation. Right arm and leg motionless, muscles not atrophied, no tremors or twitching. Pupils normal.

Superficial Reflexes.-On the right side the plantar, abdominal, cremasteric, and corneal superficial reflexes are all absent. On the left side the plantar is flexor type, corneal and abdominal present.

Deep Reflexes.-On the right side, biceps, triceps, supinatur, and wrist-jerks are all exaggerated; knee- and ankle-jerks almosi normal. On the left side all are normal.

There are no deformities. Blood pressure: systolic, 100; diastolic, 70 , pulse 72 , full. Diagnosed right hemiplegia with aphasia and an old depressed fracture on the left side noted.

The patient remained in hospital till June 2nd-that is, sixteen days-and was prepared for operation, when he died. There were no signs of abscess or other septic condition. The temperature no signs of abscess or other septic con.

was between 37 and 38 . C. throughout. symmetrical, no contraction or atrophy being observed. There was a transverse scar $3 \mathrm{~cm}$. in length adherent to the skull over was a transverse scar $3 \mathrm{~cm}$. in length adherent to the skull over
the left side of the frontal bone. Under this was found a dethe left side of the frontal bone. Under this was found a depressed fracture of the frontal bone $2 \mathrm{~cm}$. to the left of the middle line measuring $3.25 \mathrm{~cm}$. in the antero-posterior diameter and $3.9 \mathrm{~cm}$. in the transverse, about two-thirds of the depression being
on the frontal and one-third on the parietal bone. Its position was slightly above Broca's area and a little in front of and impinging on the Rolandic area. The posterior and lower segment of the wound was depressed to a greater extent than the rest, the floor of the depression gradually sloping upwards to the normal level The sharp posterior margin was smoothed and rounded. To the right of this depression there was a .healed fissure which passed forwards for $5.5 \mathrm{~cm}$. from the fronto-parietal suture. On passed forwards for $5.5 \mathrm{~cm}$. from the fronto-parietal suture. On the right of the middle line on the fronto-parietal suture the frontal bone was raised above the level of the parietal, due to
the opening of this suture by the blow, and $5 \mathrm{~cm}$. from the the opening of this suture by the blow, and $5 \mathrm{~cm}$. from the
middle line to the right a healed fissure arising from this suture and passing downwards towards the base with an inclination backwards could be seen.

Internally there was a roughly circular depression $4.2 \mathrm{~cm}$. in diameter composed of five depressed fragments and showing fissures which could not be seen externally; there was no callus formation. All the edges were smooth and no signs of sepsis could be observed. (Figs. 1 and 2.) The dura mater was not thickened nor were there any special adhesions. The brain was congested and oedematous and there was a depressed area in the congested and oedematracture. The cerebro-spinal fluid was incortex opposite the fracture. The cerebro-spinal fluid was increased in amount. The cortex of the brain appeared normal,
but on section the deeper tissues and wall of the left lateral but on section the deeper tissues and wall of the left lateral
ventricle were found lined with soft pultaceous material, and ventricle were found lined with soft pultaceous material, and
similar brownish material was found in the ventricle, the cavity similar brownish material was found in the ventricle, the cavity
of which was larger than the right. The optic thalamus' and caudate nucleus appeared very soft and broke-up on the slightest touch.

The other viscera, including the kidneys, appeared normal; there was no atheroma to be observed. There was no middle-ear disease or any other septic focus.

The brain was submitted for microscopical examination to the Pathology Department, and Dr. Serour found, in sections from the softened area, foci of sepsis with areas of interstitial haemorrhage and necrosis, and very slight thickening of the blood vessels.

This case appears to be of considerable interest from many points of view-namely, the rapid and apparently complete recovery and subsequent freedom from symptoms with a considerable area of bone depressing the cerebral cortex over the motor area; the rapid onset of cerebral softening without premonitory signs or apparent cause; the extraordinary period intervening between the injury 